Marquette University

e-Publications@Marquette

Philosophy Faculty Research and Publications

Philosophy, Department of

$7-1-2005$

\title{
Private Property and Public Interest
}

Michael Monahan

Marquette University, michael.monahan@marquette.edu

Published version. Philosophy in the Contemporary World, Vol.12, No. 2 (2005): 17-21. DOI. (C) 2005 Society for Philosophy in the Contemporary World. Used with permission. 


\section{Private Property and Public Interest}

\section{By Michael Monahan}

In this paper I explore the limitations of liberal political theory in relation to the notions of public property and public interest. I argue that the fundamentally atomistic and individualistic ontological foundations of the liberal tradition preclude any coherent notion of public goods and public interest.

\section{Introduction}

Michael Powell, son of Secretary of State Colin Powell and former head of the Federal Communications Commission, once remarked: "The night after I was sworn in, I waited for a visit from the angel of the public interest. I waited all night, but she did not come" (Masher 2002). Given that the protection of the public interest is part of the mandate of the very organization Powell chairs, his blithe dismissal of the very idea of public interest is highly significant, and more than a little bit troubling. Indeed, the FCC under Powell has sat mute while an already staggering media concentration has grown steadily worse. In radio alone, the number of companies in control of that medium has shrunk $30 \%$ since 1996 , with one company, Clear Channel, now owning more than 1,200 stations nationwide (Copps 2003). Not all of this has occurred under Powell's watch of course, but he is nevertheless remarkable for his explicit dismissal of any obligation to public good or interest. Not accidentally, at the same time that control of mass media, and thus public access to information, has become concentrated in the hands of fewer and fewer large corporations, the public goods related to media, which would include not only the airwaves and the digital spectrum, but also the physical spaces occupied by billboards, posters, and so on, are less and less in the control of the public, and increasingly in the control of these same corporate agents.

I will argue that this trend is in many important ways a result of a limitation of the dominant way of theorizing about the political that traces its roots to classical liberalism. More specifically, traditional liberal ontology, which is fundamentally atomistic and individualistic, has great difficulty capturing what a "public" might even be, let alone what goods or interests might pertain to such an entity. While there are certainly means available within this dominant tradition to at least partially address these problems, this limited ability to theorize "the public" will continue to facilitate and even obfuscate political failures of the sort described above. Therefore, what is needed is, first, an exposure of this limitation, and, second, the generation of new ways of approaching an understanding of public or common goods and our relationship 
to them. This paper is primarily an effort of the former, though I will make some gestures towards the more promising theoretical directions for the constructive project.

\section{Liberal Individualism}

The object of my critique is that body of political theory that I am here referring to as "liberal individualism." It would include the political theories of Thomas Hobbes, John Locke, J.S. Mill, John Rawls and Robert Nozick most decidedly, and at least some interpretations and elements of Immanuel Kant's and Jean-Jacques Rousseau's as well. Perhaps more importantly, it is the default understanding of the political world in the majority of Western "liberal" democracies, particularly in the U.S. It is the root of what has come to be known as neoliberalism, which implicitly, and often explicitly, informs the justification for the policies and institutions of globalization, deregulation, and free trade. The relevant feature of this body of theory in the present context is its account of the relationship between individual agents and each other, the state, and the material world. I am interested in exploring how the ontology of liberal political theory conditions and ultimately limits the very possibility of a viable concept of public or common goods.

In the interest of brevity, I offer the following general account with the understanding that it is not meant to capture any particular theory or theorist, but is intended only to carve out a broad, and necessarily imprecise, conception of political agency. Nevertheless, it does accurately represent the common features of the classical liberal cannon. Liberal individualism, as I am using the term, conceives of political agency as fundamentally atomistic. That is, social/political subjects are each self-contained and ontologically discreet political atoms. For each and every subject, that subject's fundamental ontological status can be described without reference to anything beyond itself. Each exists, as a subject, prior to any social interaction, such that social practices, bodies, and institutions can only be understood as the sum of these discreet individual components, and nothing more. All of these subjects or agents are understood as free-floating in a kind of social void, until they interact with each other through exchanges of goods, which in turn are conceptually, though not always literally, external to our agency itself. In other words, there is a hard and distinct division between what is internal to a given agent, in the sense of arising from, expressing, or being a necessary component of the self, and what is external, in the sense of being separate, distinct, contingent, and incidental to the self. The self, in short, is understood to be coherent and intelligible as such, without reference to any larger social or intersubjective context.

This in turn means that individuals exist logically, if not chronologically, prior to the social Monahan 2 
world, which is itself understood to be the result of the collected individual wills of these discreet agents. The social world arises out of these mutual exchanges of material and non-material goods between these atomistic individual agents. Indeed, to the extent that liberal theories have an anthropological project, that project is to explain how and why society came to be from some primordial pre-social state of nature. To the extent that these theories have a normative project, it is to explain the rationality of social restraint on individual interests and action purely in light of those individual interests. Within this framework, our principal means of interaction with the material world, and with each other, is through the acquisition and exchange of private property. Thus, we, as subjects, exist primarily as bearers, or potential bearers, of property, including such property as our own bodies, our rights, and our privacy. We interact with other agents through the mediation of these fundamentally external goods in the form of explicit or implicit contract, which is here understood broadly as any exchange of material and/or non-material goods for mutual benefit. All of our obligations, indeed the totality of our interactions with others, should thus be described in contractual terms. The harm of murder lies in the seizure of the property of life, the harm in discrimination lies in the curtailment of the property opportunity, and so on. Political being, in this view, amounts to the rational pursuit of self-interest through the accumulation and exchange of material and non-material goods.

Again, the details and contours of this general account will vary from theory to theory, but this basic underlying ontology is common to them all. What is important for the present project is that any social body or polity must always be understood as fundamentally reducible to its constitutive components, which are, in this context, atomistic individual subjects. At the end of the day, any social body can be understood as nothing more than a collection of individual agents engaging in explicit and implicit, and often highly sophisticated, exchanges of goods. The public is thus an amalgam of individuals, and public interest is collective individual interest. Ultimately, this means that all social phenomena can only truly be intelligible from an individual perspective, because any social entity, when it is placed under analytic scrutiny, reduces to individuals.

\section{Property: Private and Public}

Since all social phenomena within this theoretical framework are properly understood as individual phenomena, and more specifically as individual exchanges of goods, any investigation of the status of social phenomena, such as the nature of public goods or public interest, must be understood in the context of private, individual property. In terms of the specific relation to these external goods, they can only properly be understood as "ours" to the extent 
that we are capable, as individual agents, of appropriating and alienating them. That is, if we are to understand some good as our private property, we must be able to dispose of it as we see fit. If, for any reason, I am prevented from alienating my property, then it cannot rightly be understood as mine. Within the context of liberal individualism, any mention of the inalienable must always be understood in a somewhat ironic fashion. The inalienable rights enshrined in the U.S. constitution are not inalienable in any necessary or ontological sense. If they were, there would be no need to mention them in the construction of our legal institutions. Indeed, such rights are understood as guaranteed by the state in exchange for certain obligations, such as obedience to the law, on the part of the individuals who make up that state. Life, liberty, and the pursuit of happiness can be, and indeed were, alienated from significant portions of the U.S. population, and there are those who would argue that they continue to be alienated today. All of this in turn means that the limits of one's capacity to alienate one's property describes the limits of one's freedom. The more I have to exchange, in other words, the more I am able to satisfy my goals, desires, and interests. Limitations on an individual's capacity to alienate his or her property may be justified by appeal to the rights or safety of others, but they must always be understood in the strictest sense as an abrogation of freedom.

Problems arise immediately when this approach is applied to any notion of public or common goods and interests. Take, for example, a necessary commodity, like water. If a community, which must be understood solely as a collection of individual agents, lives near a large body of water, what are the means by which it may be considered a common good? Understood on an individual level, one's relation to a given object or resource is binary: either one owns it or one does not. If one owns something, one may dispose of it as one sees fit, and if one does not, one must seek permission for the appropriation of that good or object, and typically offer something in exchange for that privilege. This is the heart of the privacy of private property. If a good is understood as public rather than private, this binary relationship is no longer possible. Should I find myself living near a pond that is supposed to be common property, I may use it to a limited extent for recreation purposes, but there are myriad possible uses from which I am prohibited. I cannot, in other words, do to it whatever I wish, as I may with genuine private property. Public goods may not be easily alienated, nor may any particular individual prevent others from using or even harming them. The basic liberal individualistic model for understanding the relation between individual agents and the external world, that of property, begins rapidly to collapse. If $\mathrm{I}$, as an individual, relate to that which is external to me through the appropriation and alienation of property, and I relate to other agents through the mutual exchange of property, then all of these interactions must be subject to an accurate 
description in purely individual terms. That is, I, as an individual, must be able to undertake or reject these relations as I see fit. Public property complicates this relation, which in turn means that all public property must be understood as contrary to individual liberty, or that all public property is ultimately incoherent, or perhaps both-i.e., the incoherent concept of public property is contrary to freedom.

\section{The Incoherence of Public Property}

One may perhaps account for public property within a liberal individualist framework by extending the notion of private property to every member of the relevant polity, such that the common property becomes our collective private property. The problem with this is that no individual may relate to that public good in the usual way one relates to private property, since one may not simply appropriate or alienate it as one sees fit. Returning to the example of water, if $\mathrm{I}$, as an individual, owned the pond, then I could very well use it all to water my pumpkin patch, or dump sulfur in it, or make it my personal piranha farm. By way of comparison, I can take my television and smash it to bits with a sledgehammer because it is mine, just as I

can do whatever I wish with things that are mine. If others are in a position to prevent me from doing this without appeal to their own private property or personal safety, then it is clearly not really my private property at all. Even if they can prevent me from disposing of my property through such appeals, this prevention must be understood as an externally imposed limit on my liberty as regards that property.

However, if someone is in a position to justly prevent me from smashing my television without such appeals to their own property or interests, then that television cannot really be my property. Likewise, if someone is in a position to justly prevent me from dumping sulfur in the pond, strictly because they don't want their pond ruined, then the pond is not really my property. Nor can the pond be understood as any other's private property, since they are constrained in their use of it as well. The pond is therefore not mine, nor is there any other individual to whom it clearly belongs. In order for public property to truly be public, therefore, it cannot be a simple numeric extension of private property.

What are the options in light of this problem? One could take the common good and divide it equally such that each agent privately owns some fraction of the good. I, as an individual, could therefore be said to "own" a certain amount, say five liters, of the pond, which I may use however I wish. This may have some merit in relation to goods which are easily divisible, and for which the divided parts are distinct, but common goods are seldom like this. What I do with my five liters of pond can greatly impact others' use of it. I might, for example, Monahan 5 
dump huge amounts of chlorine in it. There are also many public goods that simply cannot be understood as divisible in this way-like airwaves. Most goods that it seems reasonable to treat as common property simply are not subject to divisibility in a way that makes this solution viable.

\section{The Institutional Custodian}

One response to this problem is to grant custody of the public good to some institution that in turn stands as the proxy private owner of that good-e.g., a public water commission or park service. Indeed this seems to be the most promising response, and is in point of fact the solution most frequently employed. The institution becomes a de facto, and usually de jure, agent, which can relate to the good or object as if it were private property. The principal difference is that the institutional agent is not pursuing its own private interest, but rather the public interest. Returning to the pond example, if an institution were created that owns the pond, and may thus dispose of that pond as it sees fit, then it is that institution that I must approach to use the pond, and that I may have to compensate for that use. I, as an individual with a certain interest in the pond, must trust that the institution will protect my interest through its ownership. Of course, the pond is still the private property of the institutional agent, which means that socalled public property, despite all this, remains a peculiar kind of private property.

There are two further problems with this solution. The first involves the relationship of private agents to this public good itself. Since the commonality of the good in such cases lies solely in the fact that it is the private property of an institution ostensibly protecting the public interest, it remains fundamentally the property of another. That is, public goods are always already not mine in the sense that we usually relate to what is mine. We interact with the institution as if it were another agent, which means that the good or property in question is at root the property someone else. There is thus no sense of ownership, and certainly no sense of stewardship, in relation to public goods on the part of those individuals who comprise the public. There is at best a kind of irony inherent in the notion of public goods that are owned by a private individual, and it is one with significant implications. Because the public goods are in fact the private goods of an institution, we relate to them in the same way that we relate to any private property not in our possession: with indifference at best, and resentment or envy at worst. If another's property is not causing me any harm, then I ignore it. Indeed, this is at the heart of liberal conceptions of social justice. On the other hand, if I understand that property to be causing me some harm or indicative of my own inadequacies, then I resent or envy it. In relation to this notion of public property, indifference is often manifested in the public tendency to ignore 
threats to public goods until it is too late, such as in the cases of the mass media, and certainly the natural environment. At the same time, resentment may also be directed toward the institution, which is seen as usurping the property rights of the individual. The present debate over the use of snowmobiles in Yellowstone exemplifies this latter phenomenon perfectly. Both sides of the issue see the park as theirs in important ways, and see the National Park Service as limiting their ability to use it as they see fit. Agent $A$ is not allowed to ride her snowmobile as much as she would like, and agent $B$ has his tranquil hike ruined by noisy snowmobiles. Regulation of public goods, therefore, is understood immediately as an imposition on the freedom of individual agents, who see their ability to access the public good as if it were private property being limited by the institutional owner.

There is a related concern involving the situation of the institutional agent within a capitalist context. In order to ensure its existence, the institution must be self-sustaining. This is difficult even when the public is indifferent to the good in question, and nearly impossible when they are resentful. The appropriation of state funds, for example, becomes contingent upon the institution's ability to demonstrate the value of the good to those in a position to deliver such funds. In the U.S., this increasingly means corporate entities and interests. In other words, the institution has in its private possession some good or resource which requires funds to maintain. In order to secure those funds, it must offer something in exchange; it must engage in contract. The public is unlikely to support the institution, since they do not understand themselves to be connected to the good or resource in the appropriate way, which is always understood to be that of private property. Thus, they are likely to either take it for granted, or seek to undermine its support. In other words, they will either be indifferent to the institution or resent it. As a result, the access to the good or service comes to be available in direct proportion to the monetary support one is able to offer. In the case of environmental resources, this means petroleum, logging, and mining interests, and in the case of the public airwaves, this means corporate media interests.

The other important issue with this conception of public property involves the theoretical account of public interest. According to this model, the institutional owner of the public property is entrusted to use that property to pursue public instead of private interest. But how is one to make sense of a public interest within the framework of liberal individualism? If social entities, such as the public, are only ever properly understood as collected individual interests, then what sense can be made of a genuinely public interest? Insofar as the public arises out of contract, out of an exchange of goods, then the public interest must be nothing more than the collected individual exchanges of goods. This means that ultimately public 
interest as such simply does not exist, there is only a kind of median or average of the individual interests of those who participate in the exchange of goods constitutive of a given polity.

In this light, Powell's statement regarding angels begins to make perfect sense. If all interests are ultimately private, then the public interest must also operate as a private interest. The use of institutional ownership makes this clear. If we cannot commonly own some property, such as the airwaves, then we must create some institution to serve as proxy private owner. If that institution is charged with serving the public interest, as is the case with the FCC, then it is prohibited from serving its own private interests. But there is no individual agent to serve as the public interest. Thus, charged with serving the public interest, Powell waits expectantly for that public to make its interests known, and it never does. There can only ever be individual interests and, given the market realities of the mass media, this means that one is best off promoting the interests of those who are in the best position to sustain the institution.

\section{Concluding Remarks}

All of this suggests an inability on the part of liberal individualism to describe any relationship to the material world other than private property. Attempts to account for common goods within this framework are tenuous at best, and ultimately serve to distance the public from the public goods themselves. This has been especially damaging in the context of mass media. As Powell's statement regarding angels makes clear, liberal individualism has a difficult time even accounting for public goods as such, let alone establishing institutions to govern their access. All agents must be described in purely atomistic terms, or the distinction between internal and external dissolves. Put simply, if we lose the binary distinction between the mine and the not mine, we lose the distinction between the me and the not me. Public goods, in threatening this internal/external distinction, can thus be understood as a direct threat to the integrity of individual agents as individual agents. Individual interests and private property are very easily accounted for, but public interests and common property cannot fit within this atomistic framework without doing it irreparable damage. One response to this is to deny the very existence of such interests and goods, as Powell seems to suggest. Another is to reject this atomistic framework.

Liberal individualism cannot account for public goods because it must treat everything as some variety of private property. This limitation is a direct result of its commitment to an atomistic ontology that understands political agency in purely individualistic terms. Within this context, private property is an all-or-nothing proposition. Either something is my property or it 
isn't, and if it isn't, then I either have no meaningful interest in it or my interests are being thwarted by some other, who is the owner of that property. What is needed, therefore, is a way of conceptualizing agency itself that is based more on relationships than possessions. Our ontology must view our sociality as constitutive of our agency, rather than incidental to it. Instead of basing all human interaction on what are fundamentally economic models involving exchanges of goods and services between atomistic units, any meaningful conception of public goods will require a theory of agency that is itself radically social instead of individualistic. In other words, the commitment to a distinct divide between the internal and external must be challenged and problematized, if not abandoned altogether. We must make explicit the ways in which our own agency and identity is dependent upon and conditioned by not only our relations with other agents, but also our relations with larger social institutions and even the paradigmatically external world of material objects. In this way, the airwaves, for example, could be mine not in the sense that I may dispose of them as I see fit, but rather in the sense that the airwaves themselves, and the manner in which they are used, condition both the development and expression of my agency; in this way they are, literally, extensions of my agency, and their misappropriation or exploitation not only harms some external good, but actually harms me. In that sense, we are all "angels of the public interest." Not in the sense of a collection of atomistic individuals pursuing our own interests, but as representatives of an intimately inter-and-intraconnected social body that is ontologically more than the sum of its parts.

\section{Endnotes}

1. One might just as easily refer to this tradition as simply "liberalism," but as I wish to stress the individualistic social ontology which serves as the foundation for classical liberalism, I have chosen this less common appellation.

2. Of course, I cannot toss it into my neighbor's yard, or drop it off a bridge onto a highway, but that is because these destinations are not mine, not because the television is not mine.

\section{Works Cited}

Copps, Michael. 2003. "Crunch Time at the FCC." The Nation Online. Last Accessed 2003 at: http://www.alternet.org/story/15015

The Masher. 2002. "Media Mash: Media 'Angels' to Descend on FCC." Alternet Online. Last Accessed 2002 at: http://www.alternet.org/story/12513 